\title{
Paraneoplastic Subacute Sensory Neuronopathy
}

National Cancer Institute

\section{Source}

National Cancer Institute. Paraneoplastic Subacute Sensory Neuronopathy. NCI

Thesaurus. Code C5420.

A sensory neuropathy caused by the effects of a distant neoplasm (usually a small cell carcinoma). It is usually caused by the production of anti-neuronal autoantibodies: antiHu (ANNA-1) or anti-CV2 (CRMP-5), which result in cytotoxic T-cell mediated destruction of dorsal root gang lia. It is the most common clinical presentation of paraneoplastic encephalomyelitis. Clinical signs include asymmetric paresthesia of the face, trunk and proximal extremities followed by lancinating pain, vibrioceptive and proprioceptive impairment, and muted reflexes. Clinical course usually follows a prog ressive neurologic deterioration which stabilizes at a level of severe, permanent disability. 